\title{
TO COMPARE THE EFFECT OF CHITOSAN, LIFESTYLE MODIFICATION, AND COMBINATION OF CHITOSAN AND LIFESTYLE MODIFICATION ON BODY MASS INDEX IN OBESE PATIENTS
}

\author{
VASUNDHARA BHOPLE ${ }^{1 *}$, DEEPAK BHOSLE ${ }^{2}$ \\ ${ }^{1}$ Department of Pharmacology, Smt. Kashibai Navale Medical College and General Hospital, Pune, Maharashtra, India. ${ }^{2}$ Department of \\ Pharmacology, Mahatma Gandhi Missions Medical College, Aurangabad, Maharashtra, India. Email: drvasu_18@yahoo.com
}

Received: 26 March 2019, Revised and Accepted: 28 May 2019

\section{ABSTRACT}

Objective: The objective of this study was to compare the effect of chitosan, lifestyle modification, and combination of chitosan and lifestyle modification on body mass index (BMI) in obese patients.

Methods: A prospective, randomized, open-label comparative study conducted for the period of 24 weeks. The study population was enrolled in three groups (chitosan $500 \mathrm{mg} \mathrm{BD}$, lifestyle modification, and chitosan $500 \mathrm{mg} \mathrm{BD}$ and lifestyle modification). Data were analyzed using " $\mathrm{t}$ "-test and ANOVA.

Results: There is a reduction in BMI in all the three groups. However, when we combined chitosan and lifestyle modification, there is pronounced reduction in BMI, which is statistically significant $(\mathrm{p}<0.0001)$.

Conclusions: Chitosan and lifestyle modification have more pronounced effect on reduction on BMI as compared to monotherapy alone.

Keywords: Body mass index, Chitosan, Lifestyle modification.

(c) 2019 The Authors. Published by Innovare Academic Sciences Pvt Ltd. This is an open access article under the CC BY license (http://creativecommons. org/licenses/by/4. 0/) DOI: http://dx.doi.org/10.22159/ajpcr.2019.v12i7.33239

\section{INTRODUCTION}

Obesity has become a major health problem worldwide, affecting people across all ages, sex, ethnicities, and races [1]. It is a medical condition in which excess body fat gets accumulated to the extent that it may have an adverse effect on health, leading to reduced life expectancy and increased morbidity and mortality due to cardiometabolic disorders. Obesity also has a serious impact on psychosocial and reproductive life of patients [2].

In 2013, an estimated 2.1 billion adults were overweight as compared to 857 million in 1980. Obesity has reached epidemic proportions in India in the $21^{\text {st }}$ century, with morbid obesity affecting $5 \%$ of the country's population. In Northern India, it was most prevalent in urban populations (male $-5.5 \%$ and female $-12.6 \%$ ) followed by the urban slums (male $-1.9 \%$ and female $-7.2 \%$ ). Obesity rates are low in rural populations (male $-1.6 \%$ and female $-3.8 \%$ ) [3]. In old age, it is associated with increased morbidity and reduction in quality of life. The relative increase in mortality is less in old as compared to young adults and body weight associated with maximal survival increases with advancing age [4].

BMI is the most commonly used measure for monitoring the prevalence of overweight and obesity at the population level. It is also the most commonly used way of estimating whether an individual person is overweight or obese. People are considered obese when their BMI exceeds $30 \mathrm{~kg} / \mathrm{m}^{2}$ [5]. In collaboration with the WHO Western Pacific Regional Office, the International Obesity Taskforce turned its attention to the Asian Pacific region in its publication. The Asia-Pacific Perspective: Redefining obesity and its treatment [6].

\footnotetext{
According to this, BMI is classified as follows:

- $\quad<18.5 \mathrm{~kg} / \mathrm{m}^{2}$ - Underweight

- $18.5-22.9 \mathrm{~kg} / \mathrm{m}^{2}$ - Normal

- $23.0-24.9 \mathrm{~kg} / \mathrm{m}^{2}$ - At-risk for obesity

- $\quad 25.0-29.9 \mathrm{~kg} / \mathrm{m}^{2}-$ Obese I

- $\quad \geq 30 \mathrm{~kg} / \mathrm{m}^{2}-$ Obese II.
}

As a person's body fat increases, both BMI and future risk of obesity-related illness also increase. BMI is an easy, cheap, and noninvasive method of assessing excess body fat [7]

Obesity leads to sedentary lifestyle and vice versa and this nexus leads to cascades of various diseases. Lifestyle modification and nutritional therapy are the mainstays of treatment. Diet quality can be improved by reducing the consumption of energy-dense foods such as those with high sugar, saturated fat and by increasing the intake of dietary fibers [8]. Although lifestyle modification and exercise are mainstays of the obesity treatment, still many patients are not able to achieve the desire goal of weight loss. There are several pharmacotherapies which are directed to treat obesity. These approaches include limiting the absorption of food, suppressing appetite, reducing food intake, and altering metabolism or increasing energy expenditure through action on central nervous system [9].

Antiobesity drugs such as sibutramine, rimonabant, orlistat, and topiramate are not recommended nowadays due to their non-safety and non-tolerability. Considering all this, in obesity management, one of the most efficient and safe methods could be reduction in fat intake, as it is directly associated with total fat consumption. A substance which acts by reducing the dietary absorption of fat is chitosan. Hence, chitosan can be used as an alternative to other antiobesity drugs.

Chitosan, glycosaminoglycans (GAGs), is colorless, odorless, and semi-crystalline flaky polymer which is obtained from the hard outer skeleton of shellfish, including crab, lobsters, and shrimp and by treating it with alkali sodium hydroxide. Chemically, it is composed of randomly distributed $\beta$-(1-4) linked D-glucosamine (deacetylated unit) and $\mathrm{N}$-acetyl-D-glucosamine (acetylation unit). It is obtained by the deacetylation of chitin through a series of enzymatic and chemical treatments. It swells up giving the feeling of satiety by physically filling the stomach [10]. It contains high amino groups (pK 6.2-7.0) and it is water soluble but not soluble in high $\mathrm{pH}$ conditions [11]. By inhibiting pancreatic lipase activity, chitosan can reduce the absorption of dietary fat in the intestines. Besides, it can bind and precipitate fat in the 
intestines so that it is not absorbed. The cationic chitosan binds with anionic carboxyl groups of fatty acids and bile acids, it also interferes with emulsification of neutral lipids such as cholesterol and other sterols by binding them with hydrophobic interaction; thus, fat and cholesterol absorption from the gastrointestinal tract are reduced [12].

Chitosan will be very effective if combine with lifestyle modification such as diet and exercise. It will give an effective result in reducing weight and ultimately reducing obesity and its associated complications. Introduction of chitosan along with lifestyle modification can avoid many risks associated with pharmacotherapy and surgical intervention in the form of bariatric surgery. A study done by Schiller et al. revealed decreased mean weight $(1 \mathrm{~kg})$ in the chitosan treatment group while it was found to be increased $(1.5 \mathrm{~kg})$ in the placebo group significantly. Furthermore, BMI was found to be significantly decreased in the treatment group [13]. In a study conducted by Pittler et al. on chitosan for weight reduction found no significant differences between groups in any outcome measures [14].

Many antiobesity drugs are available commercially, but there were no studies carried out in Aurangabad and adjoining rural areas using chitosan as an antiobesity drug. Considering the benefits of chitosan in control of obesity, we have decided to do this study on chitosan.

\section{MATERIALS AND METHODS}

A 24-week randomized comparative open-label single-center prospective clinical study was conducted in the outpatients of the Department of Medicine in collaboration with the Department of Pharmacology at Mahatma Gandhi Missions (MGMs) Medical College and Hospital, Aurangabad. It was conducted as per International Conference on Harmonization Good Clinical Practice guideline and after obtaining permission from the institutional ethics committee (MGM - ECRHS/2014/184). A total of 80 patients were screened, of which 60 patients were enrolled for the study after fulfilling the inclusion criteria. Patients were enrolled randomly by chit method in this study.

\section{Inclusion criteria}

The following criteria were included in the study:

- Patients of either gender between the age group of 20-40 years

- Patient willing to participate in the study and given written informed consent

- $\quad \mathrm{BMI}>25 \mathrm{~kg} / \mathrm{m}^{2}$

- $\quad$ HbA1c of $<5.7$.

\section{Exclusion criteria}

The following criteria were excluded from the study:

- $\quad$ BMI $<25 \mathrm{~kg} / \mathrm{m}^{2}$

- Type I and type II diabetes

- Cardiovascular diseases

- Drugs affecting weight such as steroids, oral contraceptives, antipsychotics, and antidepressants

- Patients with a history of gastrointestinal diseases and surgery

- Renal disease

- Hepatic disease, hematological disease

- Known infection with human immunodeficiency virus

- Pregnant or lactating female

- Smokers, alcoholic patients

- Thyroid disorders

- Patients who received antiobesity medication before this study.

Patients were divided into three groups and each group comprised 20 patients:

Group-I: Chitosan 500 mg BD

Group-II: Lifestyle modification

Group-III: Chitosan 500 mg BD and lifestyle modification

- Lifestyle modification: Diet chart by dietician, 30 min brisk walking daily, and salt-restricted diet

- Patients were assessed at baseline and at 24 weeks for the following: Weight, height, and BMI.
The following formula is used for BMI calculation:

$\mathrm{BMI}=$ weight in $\mathrm{kg} /(\text { height in } \mathrm{m})^{2}$

Duration of the study was 6 months. Statistical analysis was done using paired "t"-test to measure the difference within the group and ANOVA to measure differences among the group.

\section{Study flowchart}



\section{RESULTS}

A total of 60 patients of both genders enrolled and evaluated. Patients were randomly divided into three groups of 20 each.

- $\quad$ Group I = Tab chitosan 500 mg BD

- $\quad$ Group II = Lifestyle modification

- Group III = Tab chitosan 500 mg BD + Lifestyle modification.

Table 1 shows the age- and gender-wise distribution of the subjects under the study, chitosan group (Group I). About 35\% were between the age group of 20 and 30 and $65 \%$ were from 31 to 40 . Likewise, $60 \%$ were male and $40 \%$ were female.

Table 2 shows mean difference before and after treatment on BMI with chitosan as 1.67. By applying paired t-test, there is highly significant reduction in BMI $(\mathrm{p}=0.0001)$ in this group $(n=20)$.

Table 3 shows the age- and gender-wise distribution of the subjects under the study, lifestyle modification (Group II). About 50\% were between the age group of 20 and 29 and $50 \%$ were from 30 to 39 . Likewise, 50\% were male and 50\% were female.

Table 4 shows mean difference before and after treatment with lifestyle modification on BMI as 0.95. By applying paired t-test, there is highly significant reduction in BMI $(\mathrm{p}=0.0001)$ in this group $(n=20)$.

Table 5 shows the age- and gender-wise distribution of the subjects under the study, chitosan and lifestyle modification (Group III). About $40 \%$ were between the age group of 20 and 30 and $60 \%$ were from 31 to 40 . Likewise, $65 \%$ were male and $35 \%$ were female.

Table 6 shows mean difference before and after treatment with chitosan and lifestyle modification on BMI as 2.77. By applying paired t-test, there is highly significant reduction in BMI $(p=0.0001)$ in this group $(n=20)$.

Table 7 shows percent reductions in each group. In Group I, percent reduction in BMI is 5.73. In Group II, percent reduction in BMI is 3.17. In Group III, percent reduction in BMI is 2.77. 
Table 1: Sociodemographic characteristics of the study population for chitosan $(n=20)$

\begin{tabular}{ll}
\hline Age (years) & Frequency (\%) \\
$20-30$ & $7(35)$ \\
$31-40$ & $13(65)$ \\
Gender & $12(80)$ \\
Male & $8(40)$ \\
Female & \\
\hline
\end{tabular}

Mean age: $32.45 \pm 5.75$

Table 2: Effect of chitosan on body mass index before and after treatment

\begin{tabular}{llllll}
\hline Group & Mean & & $\begin{array}{l}\text { Mean } \\
\text { difference }\end{array}$ & t & p \\
\cline { 2 - 5 } & Before & After & 1.67 & 12.32 & 0.0001 \\
\hline Chitosan & $29.9 \pm 2.79$ & $28.31 \pm 2.80$ & 1.67 & & \\
\hline
\end{tabular}

Table 3: Sociodemographic characteristics of the study population for lifestyle modification $(n=20)$

\begin{tabular}{ll}
\hline Age (years) & Frequency (\%) \\
$20-30$ & $10(50)$ \\
$31-40$ & $10(50)$ \\
Gender & $10(50)$ \\
Male & $10(50)$ \\
Female & \\
\hline
\end{tabular}

Mean age: $29.00 \pm 6.15$

Table 4: Effect of lifestyle modification on body mass index before and after intervention

\begin{tabular}{llllll}
\hline Group & Mean & & $\begin{array}{l}\text { Mean } \\
\text { difference }\end{array}$ & t & p \\
\cline { 2 - 5 } & Before & After & 0.95 & 8.94 & 0.0001 \\
\hline $\begin{array}{l}\text { Lifestyle } \\
\text { modification }\end{array}$ & $30.36 \pm 3.2$ & $29.41 \pm 3.04$ & 0.95 & & \\
\hline
\end{tabular}

Table 8 shows that by applying ANOVA in Group I, II, and III, p=0.05 which means that the differences in reducing BMI in all three groups were significant.

Baseline demographic characteristics (mean \pm standard deviation) for patients in the chitosan Group I were age $32.45( \pm 5.75)$ years; lifestyle modification Group II were age 29.00 ( \pm 6.15 ); and combination of chitosan and lifestyle modification Group III were age $32.00( \pm 1.09)$. There was no significant difference between the baseline demographics of study participants.

\section{Effect on BMI in all groups}

There was a reduction in the mean body weight over a period of 6 months. In chitosan group (GroupI), body weight was reduced from $29.98 \pm 2.79$ at baseline to $28.31 \pm 2.80$ which was statistically significant $(P<0.0001)$ when compared with baseline measurements. The percent reduction in BMI was $5.73 \%$. In lifestyle modification group (Group II), body weight was reduced from $30.36 \pm 3.20$ at baseline to $29.41 \pm 3.04$ which was statistically significant $(P<$ 0.0001 ) when compared with baseline measurements. The percent reduction in BMI was $3.17 \%$. In chitosan and lifestyle modification group (Group III), body weight was $32.67 \pm 0.67$ at baseline and $29.90 \pm 0.63$ was at the end of the study which was statistically significant $(P<0.0001)$. The percent reduction in BMI was $2.77 \%$.

\section{DISCUSSION}

Obesity is the most common metabolic disorder which results from excess accumulation of adipose tissue in the body. The prevalence of
Table 5: Sociodemographic characteristics of the study population for chitosan therapy and lifestyle modification intervention $(n=20)$

\begin{tabular}{ll}
\hline Age (years) & Frequency (\%) \\
$20-30$ & $8(40)$ \\
$31-40$ & $12(60)$ \\
Gender & $13(65)$ \\
Male & $7(35)$ \\
Female &
\end{tabular}

Table 6: Effect of chitosan therapy and lifestyle modification intervention on body mass index before and after treatment

\begin{tabular}{|c|c|c|c|c|c|}
\hline \multirow[t]{2}{*}{ Group } & \multicolumn{2}{|l|}{ Mean } & \multirow{2}{*}{$\begin{array}{l}\text { Mean } \\
\text { difference }\end{array}$} & \multirow[t]{2}{*}{$\mathbf{t}$} & \multirow[t]{2}{*}{$\mathbf{p}$} \\
\hline & Before & After & & & \\
\hline $\begin{array}{l}\text { Chitosan } \\
\text { and lifestyle } \\
\text { modification }\end{array}$ & $32.67 \pm 0.67$ & $29.90 \pm 0.63$ & 2.77 & 14.17 & 0.0001 \\
\hline
\end{tabular}

Table 7: Percentage reduction in body mass index in all three groups

\begin{tabular}{lll}
\hline Group & $\begin{array}{l}\text { Mean difference } \\
\text { (before and after treatment) }\end{array}$ & $\begin{array}{l}\text { Percentage } \\
\text { reduction in BMI (\%) }\end{array}$ \\
\hline Group I & 1.67 & $5.73 \downarrow$ \\
Group II & 0.95 & $3.17 \downarrow$ \\
Group III & 8.85 & $2.77 \downarrow$ \\
\hline
\end{tabular}

BMI: Body mass index

Table 8: Comparison for all three groups by ANOVA

\begin{tabular}{llc}
\hline Comparison groups & F & p \\
\hline Group I versus II versus III & 3.763 & $0.05^{*}$ \\
\hline $\mathrm{p}>0.05$ - Not significant, ${ }^{*} \mathrm{p}<0.05-$ Significant, & ${ }^{* * *} \mathrm{p}<0.001-$ Highly significant
\end{tabular}

obesity is increasing throughout the world. It is associated with many comorbid conditions such as type II diabetes, cardiovascular diseases, hypertension, and hyperlipidemia and musculoskeletal diseases.

Obesity has reached epidemic proportions in India in the $21^{\text {st }}$ century, with morbid obesity affecting $5 \%$ of the country's population. Urbanization, modernization, and changing dietary pattern have been associated with increased prevalence of obesity. Obesity rates were the lowest in rural populations than the urban population. Socioeconomic status also had an effect on the growing epidemic of obesity. Obesity in old age is associated with increased morbidity, mortality, and reduction in quality of life due to musculoskeletal problems.

There are many methods for the assessment of obesity, but BMI is the most commonly used method to classify obesity. By this, we can come to know the people who are at high risk of developing the diseases which are mainly associated with obesity. BMI cutoff points for obesity have many uses, which are primarily applicable to Asian countries. They are used clinically to screen high-risk individuals for cardiac metabolic disorder, to identify individuals for absolute risk assessment, and to determine the type and intensity of treatment. Raised BMI also increases the risks of cancer of the breast, colon, prostate, endometrium, kidney, and gallbladder.

Lifestyle modification plays an important role in the treatment of obesity. It mainly consists of brisk walking for $30 \mathrm{~min}$ and a lowcalorie diet as gave the dietician. Physical activity plays a critical role in improving cardiovascular health in both the average weight and obese 
individuals. Increased physical activity helps to lower the accumulation of fats in the body. Low-calorie diet provides a calorie deficit of $500-1000 \mathrm{kcal} /$ day from maintenance requirement and is important for weight loss and prevention of weight regain. Low-fat diets provide $25 \%-30 \%$ of calories from fat. They produce weight loss primarily by decreasing caloric intake. Very low-calorie diet of 200-800 kcal/day is often in the form of liquid nutritional supplement and results in the most rapid weight loss. It is appropriate only when the patient faces a major health risk and the physician has determined that such a diet can be used safely.

Chitosan is the drug which is used for the treatment of obesity. It is GAGs. Chemically, it is composed of randomly distributed $\beta-(1-4)$ linked D-glucosamine (deacetylated unit) and N-acetyl-D-glucosamine (acetylation unit). It is obtained by the deacetylation of chitin through a series of enzymatic and chemical treatments. It swells up giving the feeling of satiety by physically filling the stomach. It inhibits pancreatic lipase activity and reduces the absorption of dietary fat in the intestines. It can bind and precipitate fat in the intestines so that it is not absorbed. It also helps for reduction in the absorption of fat and cholesterol. Thus, it helps in the reduction of weight.

Antiobesity drugs such as sibutramine, rimonabant, orlistat, and topiramate are not recommended nowadays due to their non-safety and non-tolerability. In the present study, we found that administration of chitosan for 24 weeks, in all three groups decreases BMI. The difference was statistically highly significant $(\mathrm{p}=0.0001)$. When we had use chitosan as monotherapy, these results were comparable to the study conducted by Schiller et al., [13] which revealed that decreased mean weight in the treatment group and also BMI were found to be significantly decreased in the absence of other lifestyle modifications. Furthermore, combination therapy of chitosan and lifestyle intervention for 24 weeks, there was a decrease in BMI and the difference was statistically highly significant $(p=0.0001)$. This result was correlated with the study conducted by Giustina and Ventura [15] with chitosan and low-caloric diet, which revealed that greater reduction in mean body weight and BMI, which were statistically significant. When we have compared all the groups in this study, we found that the results were statistically significant after 24 weeks of therapy, but combined effect was more significant as compared to monotherapy. There were no adverse events during the study. No dropout was observed, which states that overall, the study treatment was safe and well tolerated by all study subjects.

Limitation of the study is small sample size and it is a single-center study.

\section{CONCLUSIONS}

In the present study, chitosan and lifestyle modification intervention as monotherapy and in combination reduce BMI significantly after 24 weeks of treatment. The advantage of using combination therapy seen in Group III as it has reduced BMI to a greater extent. The result of our study reveals that a combination of chitosan and lifestyle modification produced a more pronounced effect on BMI as compared to monotherapy. In our study, we found that chitosan, lifestyle modification, and combination of both have effect on reduction of BMI.
This can be helpful for the treatment of obesity, which will help to reduce high risk of developing diseases associated with obesity. From this study, we conclude that chitosan and lifestyle modification alone have a significant reduction in BMI, but more pronounced effect has seen with the combination of chitosan and lifestyle modification.

\section{AUTHORS' CONTRIBUTIONS}

Dr. V. Bhople has performed the work presented here. Dr. D. Bhosle has guided and contributed to the data analysis and interpretation of this project.

\section{CONFLICTS OF INTEREST}

This study has no conflicts of interest to be declared.

Its non-sponsored study.

\section{REFERENCES}

1. Bollapragada MK, Shantaram M, Kumar S. Obesity: Development, epidemiology, factors affecting, quantity, health hazards, management and natural treatment a review. Int J Pharm Pharm Sci 2017:9:12-26.

2. Caballero B. The global epidemic of obesity: An overview. Epidemiol Rev 2007;29:1-5

3. Yadav K, Krishnan A. Changing patterns of diet, physical activity and obesity among urban, rural and slum populations in north India. Obes Rev 2008;9:400-8.

4. Kopelman PG, Caterson ID, Stock MJ, Dietz WH. Clinical Obesity in Adults and Children. Hoboken, New Jersey: Blackwell Publishing; 2005. p. 493.

5. World Health Organization: The Problem of Overweight and Obesity Part I. Vol. 2. Washington, DC: World Health Organization; 2000. p. 6.

6. Flegal KM, Carroll MD, Ogden CL, Johnson CL. Prevalence and trends in obesity among US adults, 1999-2000. JAMA 2002;288:1723-7.

7. Steering Committee. The Asia-Pacific Perspective: Redefining Obesity and its treatment. Melbourne: International Diabetes Institute; 2000.

8. Barness LA, Opitz JM, Gilbert-Barness E. Obesity: Genetic, molecular, and environmental aspects. Am J Med Genet A 2007;143A:3016-34.

9. Astrup A. Dietary composition, substrate balances and body fat in subjects with a predisposition to obesity. Int J Obes Relat Metab Disord 1993;17 Suppl 3:S32-6.

10. Heber D. Herbal preparations for obesity: Are they useful? Prim Care 2003;30:441-63

11. Eldin MS, Omer AM, Wassel MA, Tamer TM, Elmonem MS, Ibrahim SA, et al. Novel smart $\mathrm{pH}$ sensitive chitosan grafted alginate hydrogel microcapsules for oral protein delivery: Evaluation of the swelling behaviour. Int J Pharm Pharm Sci 2015;7:320-6.

12. Ylitalo $R$, Lehtinen $S$, Wuolijoki E, Ylitalo $P$, Lehtimäki $T$. Cholesterol-lowering properties and safety of chitosan. Arzneimittelforschung 2002;52:1-7.

13. Schiller RN, Barrager E, Schauss AG, Nichols EJ. A randomized, double-blind, placebo-controlled study examining the effects of a rapidly soluble chitosan dietary supplement on weight loss and body composition in overweight and mildly obese individuals. J Am Nutraceut Assoc 2001;4:42-9.

14. Pittler MH, Abbot NC, Harkness EF, Ernst E. Randomized, double- blind trial of chitosan for body weight reduction. Eur J Clin Nutr 1999;53:379-81.

15. GiustinaA, VenturaP. Weight-reducingregimensinobese subjects:Effects of a new dietary fibre integrator. Acta Toxicol Ther 1995;16:199-214. 